\title{
Synthesis of peptides glycated at Lys residues
}

Daria Roshchupkina $^{1}$, Yulia Filatova ${ }^{1}$, Alexey Chistov $^{1}$, Tatana Melnikova ${ }^{2}$, Ekaterina Kolesanova ${ }^{1}$

${ }^{1}$ Institute of Biomedical Chemistry (IBMC), Moscow, Russia

${ }^{2}$ N.D. Zelinsky Institute of Organic Chemistry, Moscow, Russia

https://doi.org/10.17952/35EPS.2018.076

\section{Summary}

Since the most common in vivo glycated protein products represent the ones glycated at Lys residues, we studied several approaches for the preparation of HSA fragments and artificial glycated peptide haptens containing glycated (1-deoxyfructosyl-, or Amadori product (AM), carboxymethylated (CM) and carboxyethylated (CE)) Lys residues. The studied approaches were: 1) modification by glucose in methanol solution [1]; 2) Schiff base formation with further reduction [1-2]; 3) alkylation (for CM-and CE-modifications) [3-4]. Peptide modification versus Fmoc-Lys modification with further application of the latter in SPPS evaluated. Yields and purity of glycated peptides obtained with the use of different approaches were compared.

\section{Introduction}

Diabetes represents a serious medico-social and economic problem in all countries over the world. Despite the fact that there are systems for early diagnosis of this disease, there is still no adequate control of treatment efficiency and prognosis of complications. Elevated blood glucose levels result in increased protein nonenzymatic glycation in diabetic patients. Glycated hemoglobin relative content is recognized as a "gold standard" in diabetes diagnostics by WHO. However, in certain cases this parameter does not correlate well with the severity of hyperglycemia and, because of the long life of erythrocytes and hemoglobin in blood, cannot be used for a midterm evaluation of a treatment efficiency. Glycated human serum albumin (HSA) represents another possible marker of diabetes, suitable for the midterm treatment efficiency evaluation, as well as for diabetes complication prognoses [5-6]. The problem of the glycated HSA use as a diagnostic marker lies in its poorly studied in vivo glycation. Nowadays HSA glycation studies by proteomic methods are in progress, but in order to get accurate quantitative results, glycated HSA fragments are needed as standards and calibrants for LC-MS analyses and as antigens for producing specific antibodies for the selective detection of glycated proteins.

\section{Experimental}

Fragments of HSA used for the preparation of glycated peptides are shown in Table 1.

Peptides were prepared by SPPS by the FastMoc procedure on 433A synthesizer (Applied Biosystems), were purified by HPLC and analyzed by LC-MS and MS/MS.

Table 1: Peptides, sites and types of modifications.

\begin{tabular}{|c|c|c|c|c|}
\hline Peptides & Sequence & Modified site & Type of modification & Peptide $\mathrm{MH}^{+}$; Da \\
\hline $\begin{array}{c}\text { HSA fragment } \\
549-558 \\
\text { Shown to be highly } \\
\text { glycated in diabetes }\end{array}$ & KQTALVELVK & $\begin{array}{l}\mathbf{K}_{\mathbf{A M}^{549}}{ }^{5 T A L V E L V K} \\
\mathbf{K}_{\mathbf{C M}}{ }^{549} \text { QTALVELVK } \\
\mathbf{K}_{\mathbf{C E}}{ }^{549} \text { QTALVELVK }\end{array}$ & $\begin{array}{l}\text { AM-Amadori product } \\
\text { (1-deoxyfructosylated) } \\
\text { CM-carboxymethylation } \\
\text { CE-carboxyethylation }\end{array}$ & $\begin{array}{l}1290.74 \\
1186.70 \\
1200.71\end{array}$ \\
\hline $\begin{array}{l}\text { Artificial peptides } \\
\text { for producing anti- } \\
\text { (glycated Lys) } \\
\text { antibodies }\end{array}$ & GSGSGK(amide) & $\begin{array}{l}\text { GSGSGK}_{\text {AM}} \text { (amide) } \\
\text { GSGSGK}_{\text {CM(amide) }} \\
\text { GSGSGKCE(amide) }\end{array}$ & $\begin{array}{l}\text { AM-Amadori product } \\
\text { CM-carboxymethylation } \\
\text { CE-carboxyethylation }\end{array}$ & $\begin{array}{l}653.40 \\
549.29 \\
563.30\end{array}$ \\
\hline
\end{tabular}

Three approaches were used for the preparation of $\varepsilon$-Lys-Amadori products (3).

1. Incubation of synthesized (1) and deprotected (except $\mathrm{N}$-terminalFmoc-group) Lys-containing peptide (2) in saturated methanolic glucose solution at 60-70oC [1] (Scheme 1, Approach A).

2. Reductive amination of Lys $\varepsilon$-amino group in a free $\alpha$-N-Fmoc-protected peptide (2) by the protected aldoketose $(4,5)$ in the presence of $\operatorname{Nax}(\mathrm{CN}) \times B H 4$ in methanol at room temperature with further peptide and 
1-deoxyfructosyl moiety total deprotection [1] (Scheme 1, Approach B).

Protected 2,3:4,5-di-O-isopropylidene-aldehydo-b-D-arabino-hexosulo-2,6-pyranose (4) was obtained by the method described in [7].

3. Reductive amination of Lys $\varepsilon$-amino group in the resin-attached peptide with selectively deprotected Lys $\varepsilon$-amino-group $(6,7)[2]$ (Scheme 1, Approach C).

The first approach gave the worst results: the lowest yield of a mixture of peptide glycation products, which were difficult to separate by HPLC after the elimination of glucose by adsorbing the peptides on C18-silicagel (ZipTips) and extensive sorbent washing by water.

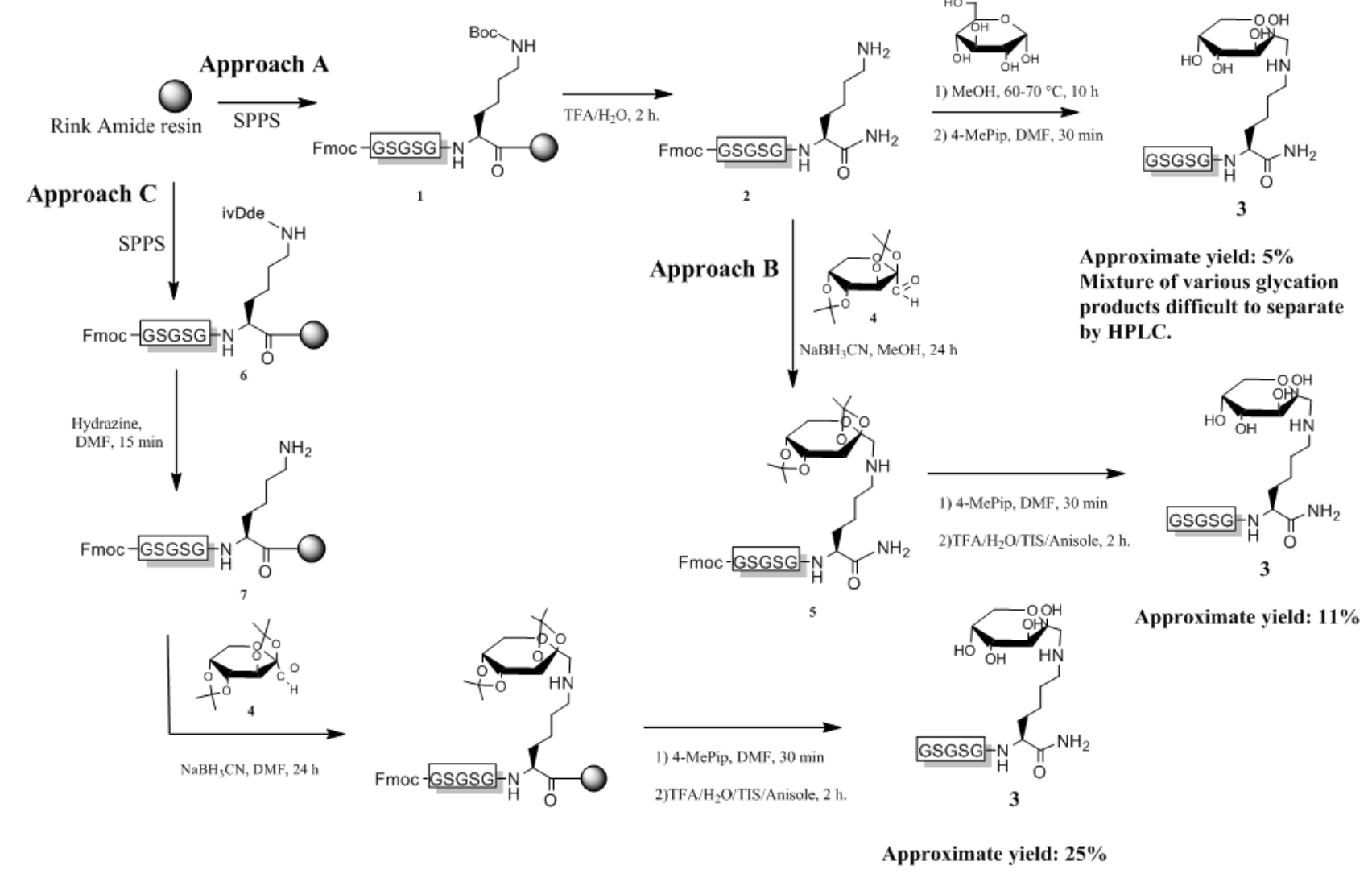

Scheme 1: Synthesis of Amadori products.

Although syntheses of Lys-CM- and CE-modified peptides are described in several papers, the majority of these approaches are time-consuming and suffer from poor yields. The most frequently used method is the alkylation of Lys $\varepsilon$-amino group with Boc or Nosyl (4-nitrobenzene sulfonyl, Ns) protection (to avoid dialkylation) by $\alpha$-bromo-acetic or -propionic acid esters. We compared the application of this method to the preparation of Lys-CM- and Lys-CE-containing peptides. In this study, we used the 4-nitrobenzenesulfonyl (Nosyl) group for protection $\varepsilon$-amino group of Lysine residue [3]. This group allows specific monoalkylation of the $\varepsilon$-amine.

In this work, we compared and evaluated two approaches for obtaining CM- and CE-modified peptides (11).

1. Fmoc-Lysine modification (8) with its further application in SPPS [3-4] (Scheme 2, Approach D).

2. Alkylation of $\varepsilon$-Ns-protected Lys residue in the on-resin peptide (9) with further peptide deprotection(10) and detachment from the resin (11) [3-4] (Scheme 2, Approach E).

Approximate yields in both cases were almost the same, but the second approach was more convenient, cheaper and faster than the first one. 


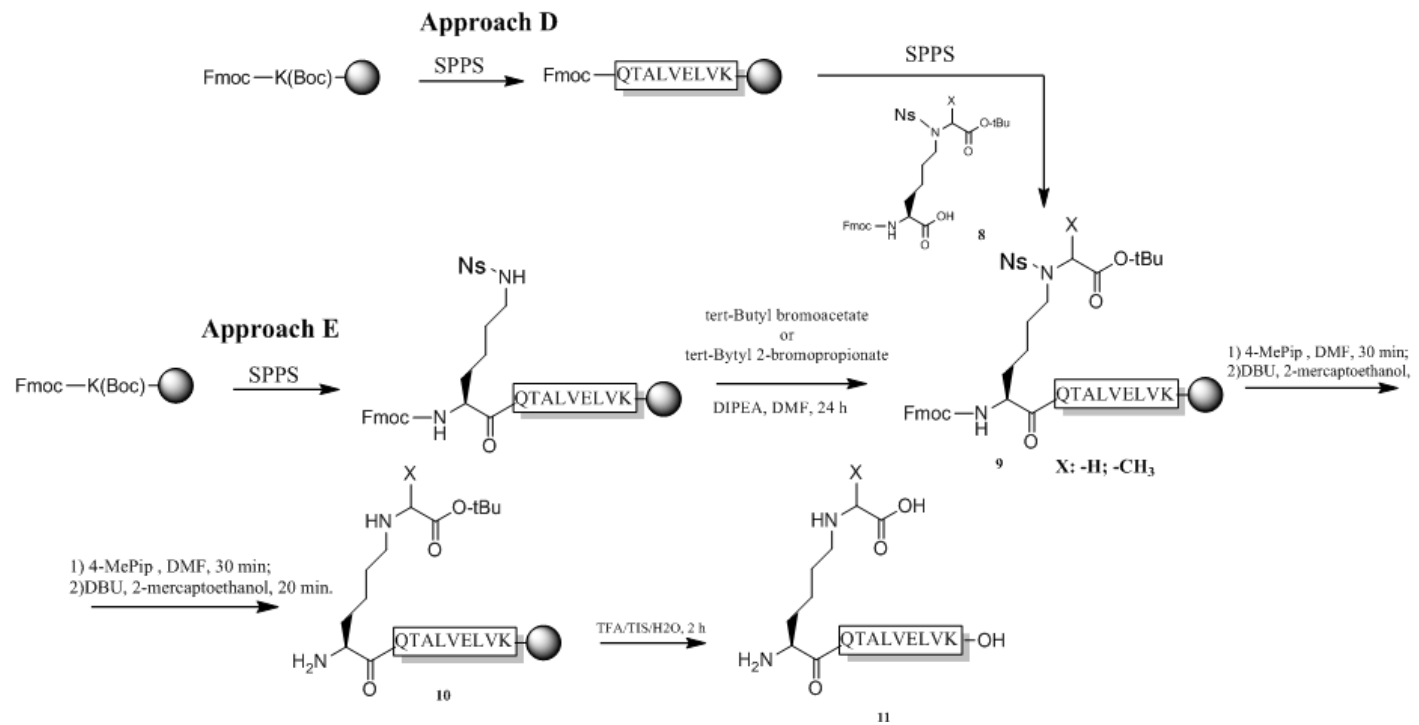

Scheme 2: Synthesis of peptides containing carboxymethylated (CM) and carboxyethylated (CE) Lys residues.

However, we could not obtain CE-modified peptides by both approaches, though the $\varepsilon$-CE- $\varepsilon$-Ns- $\alpha$-FmocLys (10) was obtained and its structure was confirmed. A model experiment with the treatment of (8) with trifluoroacetic acid/water mixture $95 \% / 5 \%$ (as for peptide detachment from the resin) showed that a possible elimination of carboxyethyl group from Lys $\varepsilon$-amino group during TFA treatment occurred (Scheme 3), and it didn't allow the preparation of carboxymethylated peptide by the on-resin modification.

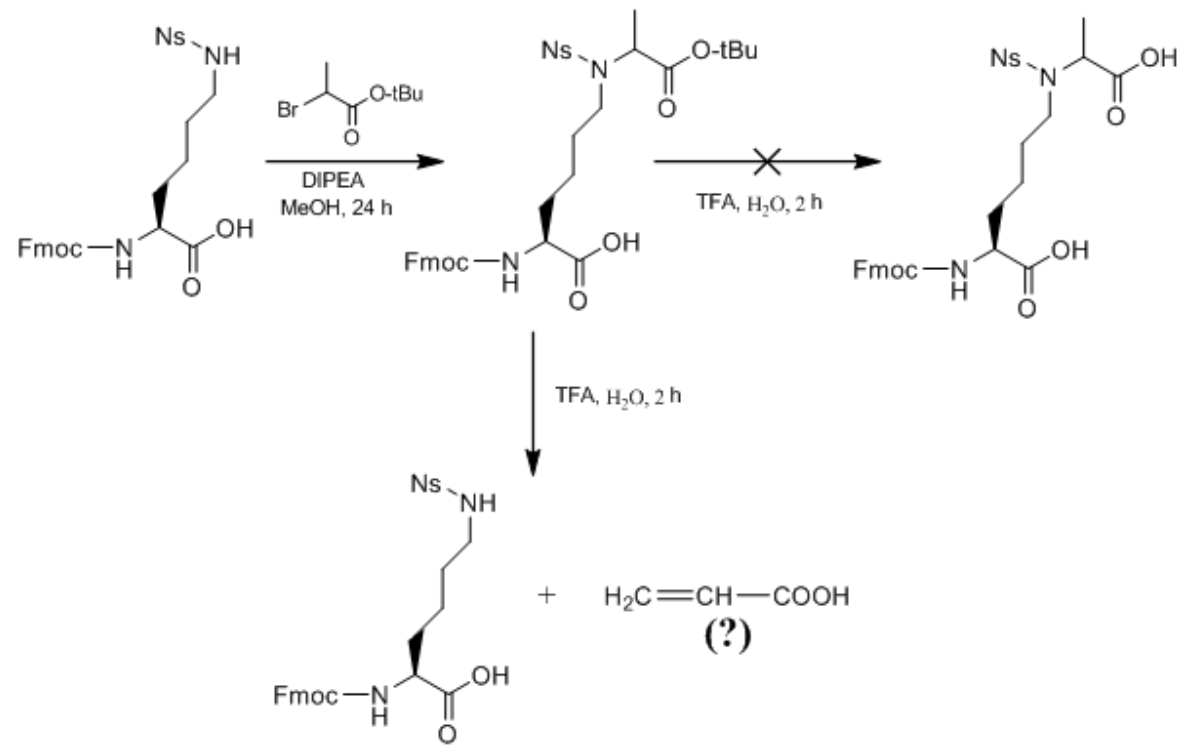

Scheme 3: Model experiment.

\section{Results}

1) Modifications of peptides by glucose in saturated solution resulted in low yields and a mixture of various glycation products difficult to separate selectively by HPLS.

2) Lys glycation in on-resin peptides was shown to be the most efficient procedure compared to a separate preparation of glycated Fmoc-Lys with its further application in SPPS and free peptide glycation.

3) Carboxyethyl group elimination from Lys $\varepsilon-\mathrm{NH}_{2}$ group was observed during TFA treatment that did not allow the preparation of carboxyethylated peptides by on-resin modification.

4) The suitability of each studied approach depends on the type of glycation and the position of the modified Lys residue in peptide chains. 


\section{Acknowledgments}

The study was performed in the framework of the Program for Basic Research of the Russian Academies of Sciences for 2013-2020. Peptide synthesis was done with the use of the equipment of the "Human Proteome" Core Facility of the Institute of Biomedical Chemistry (Moscow, Russia) supported by the Ministry of Education and Science of the Russian Federation (unique project ID RMEFI62117X0017).

\section{References}

1. A. Jakas et al. / Carbohydrate res. 343 (2008) 2475-2480 DOI:10.1016/j.carres.2008.07.003

2. P. Stefanowicz et al. / TetrahedronLetters 48 (2007) 967-969 DOI:10.1016/j.tetlet.2006.12.022

3. M. Kamalov et al. / Synlett 25 (2014) 1835-1838 DOI:10.1055/s-0033-1378305

4. H. Kaur et al. / Acc. Chem. Res. 49 (2016) 2199-2208 DOI: 10.1021/acs.accounts.6b00366

4. T. M. Woods et al. /Org. Lett. Vol. 14, No. 22 (2012) 5740-5743 DOI:10.1021/ol302745f

5. A. M. Korwar et al. / Mol. \& Cell. Proteomics 14.8, 201 DOI:10.1074/mcp.M115.050518

6. J. Anguizola et al. /Clin Chim Acta. (2013) October 21; 0: 64-76 DOI:10.1016/j.cca.2013.07.013

7. R.W.Lowe et al. /Carbohydrate res., 28 (1973) 281-293 DOI:10.1016/S0008-6215(00)82783-4 